
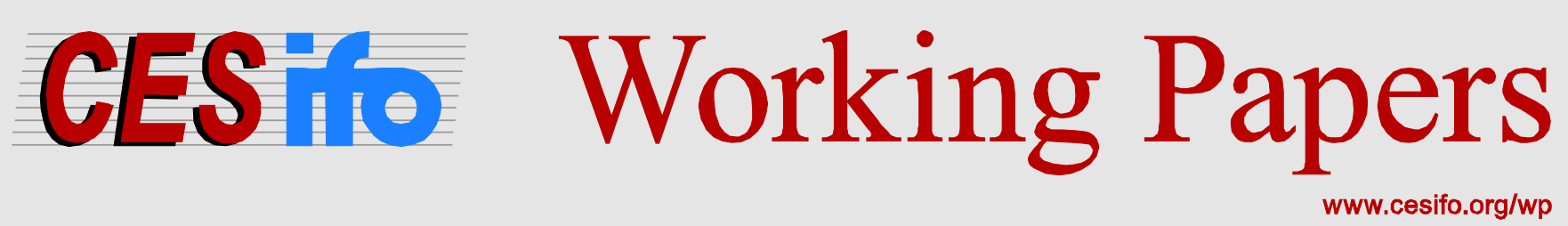

\title{
Smells Like Fiscal Policy? Assessing the Potential Effectiveness of the ECB's OMT Program
}

\author{
Nikolay Hristov \\ Oliver Hülsewig \\ Thomas Siemsen \\ Timo Wollmershäuser
}

CESIFO WORKING PAPER NO. 4628

CATEGORY 7: MONETARY POLICY AND INTERNATIONAL FinANCE

FEBRUARY 2014

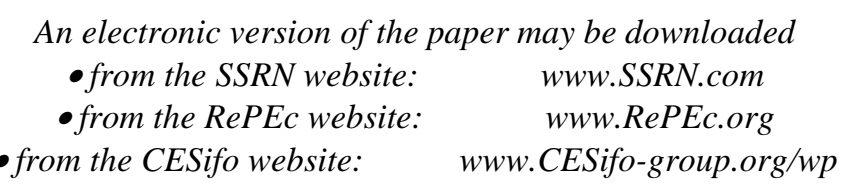




\title{
Smells Like Fiscal Policy? Assessing the Potential Effectiveness of the ECB's OMT Program
}

\begin{abstract}
This paper explores the potential effectiveness of the ECB's Outright Monetary Transaction (OMT) program in safeguarding an appropriate monetary policy transmission. Since the program aims at manipulating bank lending rates by conducting sovereign bond purchases on secondary markets, a stable relationship between bank lending rates and government bond rates is of prime importance. Using vector autoregressive models with time varying parameters (TVP-VAR) we evaluate the stability of this relationship by focusing on the reaction of bank lending rates to movements in government bond rates over the period 20032013. Our results suggest that the potential success of OMTs in restoring the monetary transmission mechanism is limited as the link between bank lending rates and government bond rates has substantially weakened since the end of 2008.
\end{abstract}

JEL-Code: E420, E430, E440, E580, E630.

Keywords: European Central Bank, OMT program, time varying parameter vector autoregressive model, interest rate pass-through.

\author{
Nikolay Hristov \\ Ifo Institute - Leibniz-Institute for \\ Economic Research at the \\ University of Munich \\ Germany - 81679 Munich \\ hristov@ifo.de
}

Thomas Siemsen

Ludwig-Maximilians-University Munich

Seminar for Macroeconomics

Ludwigstraße 28

Germany-80539 Munich

thomas.siemsen@econ.lmu.de
Oliver Hülsewig*

Munich University of Applied Sciences

Am Stadtpark 20

Germany-81243 Munich

Oliver.Huelsewig@hm.edu

Timo Wollmershäuser

Ifo Institute - Leibniz-Institute for

Economic Research at the

University of Munich

Germany - 81679 Munich

wollmershaeuser@ifo.de

*corresponding author

January 24, 2014

We are grateful to the participants of the research seminar at the University of Giessen for very helpful comments and suggestions. 
"Within our mandate, the ECB is ready to do whatever it takes to preserve the euro. And believe me, it will be enough."

- Mario Draghi, July 26, 2012

\section{Introduction}

The European Central Bank (ECB) launched its Outright Monetary Transaction (OMT) program on September 6, 2012 with the objective to safeguard an appropriate monetary policy transmission (European Central Bank, 2012a). ${ }^{1}$ Tensions emerged as banks in the euro area have become reluctant to decrease lending rates after mid 2008 despite the vigorous cut in policy rates, which has hampered the transmission of impulses coming from the accommodative monetary policy. ${ }^{2}$ OMTs are aimed at reestablishing an efficient transmission of monetary policy to the real economy by means of sovereign bond purchases on secondary markets, which seek to lower bank lending rates by reducing government bond rates.

This paper explores the potential effectiveness of the ECB's OMT program in restoring the monetary transmission mechanism. Using vector autoregressive models with time varying parameters (TVP-VAR) for several euro area periphery countries we examine the reaction of bank lending rates to movements in government bond rates. The strength and the stability of the relationship between these interest rates is of major importance in the context of the OMT program. For if the link between bank lending rates and sovereign bond yields would turn out to have been weak over the past years, then tensions in periphery countries' bond markets should not be viewed as the primary reason for the irresponsiveness of these countries' bank lending rates to monetary policy. Accordingly, in that case, it would be questionable whether the announcement of the OMT program was necessary and whether its potential benefits in terms of lowering bank lending rates through announcements or even actual interventions in sovereign bond markets can outweigh the potential risks associated with this new monetary policy measure.

The ECB's OMT program concentrates on sovereign bond markets of euro area member countries, which face difficulties in issuing government bonds at sustainable

\footnotetext{
${ }^{1}$ Officially, the ECB states that "OMTs aim at safeguarding the transmission mechanism in all euro area countries and the singleness of the monetary policy" (European Central Bank, 2012a, p. 7).

${ }^{2}$ The ECB identified obstacles in the monetary transmission mechanism as the spreads between bank lending rates over money market rates started to increase sharply since the mid of 2008 albeit the policy rate on the main refinancing operations was reduced by 375 basis points between July 2008 and May 2013. See Hristov, Hülsewig, and Wollmershäuser (2012a), Aristei and Gallo (2012) or Blot and Labondance (2013) for a discussion.
} 
interest rates due to tensions that possibly originate from fears of the reversibility of the euro (European Central Bank, 2012b). OMTs are in principle unlimited (Deutsche Bundesbank, 2012), however, a precondition for support will be compliance with a EFSF/ESM program that embeds strict conditionality (Petch, 2013). The program will be concentrated on purchases of government bonds referring to the shorter part of the yield curve, with maturities of between one and three years. ${ }^{3}$

The OMT program rests on the notion that lending rates set by banks are influenced by movements in government bond rates (European Central Bank, 2012a). Thus, bank lending rates in euro area member countries may react sluggishly to a decline in policy rates due to fears of adverse developments affecting the sovereign that undermine the monetary transmission mechanism. The link between bank lending rates and government bond rates is explained by the impact of government bond markets on financing conditions (Neri, 2013; Albertazzi, Ropele, Sene, and Signoretti, 2012; European Central Bank, 2012a). First, banks may suffer from write-offs in their balance sheets after a devaluation of sovereign bonds, which possibly deteriorates the capital position. Second, the rating of banks may be downgraded following a reduction in the rating of the sovereign causing an increase of the risk premium on external financing. Third, the collateral base of banks may be damaged due to tensions in sovereign bond markets which limits the access to liquidity. Finally, since savers may regard sovereign bonds as close substitutes for deposits, an increase in sovereign bond rates likely triggers a raise in deposits rates. Consequently, bank lending rates may increase due to distortions in sovereign bond markets that cause raising deposit rates. The OMT program is aimed at removing the adverse consequences of these effects on the transmission of monetary policy that become relevant once sovereign risk intensifies.

However, in the view of critics like Weidmann (2013), Sinn (2013), Konrad (2013), Fuest (2013) or Uhlig (2013), the ECB has breached its mandate by announcing potentially unlimited sovereign bond purchases. The OMT program constitutes a step too far into the terrain of fiscal policy (Siekmann and Wieland, 2013), which violates European law (Art. 123 paragraph 1 TFEU) according to which monetary financing of sovereign entities is strictly prohibited. Political independence of the ECB is jeopardized by the support of fiscal policies in euro area crisis countries as selected sovereign bond purchases may give rise to moral hazard because of a lack of pressure to implement necessary structural reforms due to subsidized sovereign bond rates (Konrad, 2013; Fuest, 2013). The task of the ECB excludes the guarantee that euro area member countries remain sovereign (Weidmann, 2013). Distributional

\footnotetext{
${ }^{3}$ European Central Bank (2012b) for a survey of the modalities of OMTs.
} 
effects across euro area member countries likely emerge. Since the OMTs are concentrated on sovereign bond purchases for euro area crisis countries this counteracts the neutrality of monetary policy (Sinn, 2013). Moreover, the adherence of OMTs to the compliance of euro area crisis countries with a EFSF/ESM program is hardly credible (Uhlig, 2013). Euro area crisis countries may refuse to fulfill any obligations but still benefit from sovereign bond purchases, which are conducted to avoid contagion effects. Accordingly, conditionality in case of euro area crisis countries moving to the edge of national bankruptcy is likely sacrificed (Konrad, 2013). A reallocation of resources across euro area member states may be the consequence. Finally, monetary policy transmission is characterized by intricacies. Thus, differences in the level of sovereign bond rates may potentially reflect economic fundamentals rather than a broken monetary transmission mechanism (Deutsche Bundesbank, 2012). A quantitative proof concerning the irrationality of the spreads between sovereign bond rates is difficult to provide.

In contrast, supporters of the ECB's OMT program like De Grauwe (2013) emphasize that OMTs enable the monetary authorities to act as a lender of last resort in the government bond markets, which eliminates the risk of a liquidity squeeze. Financial markets are frequently characterized by multiple equilibria (Fratzscher, Giavazzi, Portes, Weder di Mauro, and Wyplosz, 2013), where fundamentals of sovereigns are judged differently such that more than one price charged on sovereign debt may exist. The announcement of the OMT program has induced a shift to a favorable equilibrium due to the commitment of unlimited sovereign bond purchases (Giavazzi, Portes, Weder di Mauro, and Wyplosz, 2013), which has immediately stopped the increase in sovereign bonds spreads. Moreover, signaling the willingness to take over sovereign liquidity risk has contributed to restore financial market confidence. Fratzscher (2013) points out that the OMT program enables the ECB to fulfill its primary objective of maintaining price stability. The use of unconventional monetary policy measures such as sovereign bond purchases is required during a crisis to ensure that the monetary transmission mechanism functions. Thus, the OMT program is a monetary policy instrument, and not a fiscal policy tool (Fratzscher, Giavazzi, Portes, Weder di Mauro, and Wyplosz, 2013).

Our analysis abstracts from issues concerning the legitimacy of the ECB's OMT program as we use an agnostic approach to assess the potential effectiveness of OMTs in restoring the monetary transmission mechanism. We consider various euro area periphery countries to explore the reaction of bank lending rates offered to non-financial cooperations with different maturities to shocks in government bond rates over the period 2003-2013 to assess the stability of the link between these 
interest rates. The set of countries includes Ireland, Italy, Portugal and Spain, which might be considered possible candidates for the OMT program. ${ }^{4}$ Overall, our results suggest that the potential effectiveness of the OMT program in safeguarding an appropriate monetary policy transmission is limited. While bank lending rates reacted only sluggishly to changes in government bond rates before the start of the government bond market turmoil in 2010, their responsiveness to movements in sovereign bond rates has further weakened substantially thereafter. For example, a decrease of one percentage point in the interest rate on peripheral government bonds with maturities of 1 to 3 years induced a maximum decrease in the shortterm periphery bank lending rate of about -0.40 percentage points in 2006 , but only a decrease of -0.25 percentage points in 2013. We also simulate an out-of-sample policy experiment to approximate the amount of government bonds that the ECB would have to purchase under the OMT program, such that periphery government bond rates would immediately drop to the level of the core government bond rate observed in April 2013. We show that while periphery bank lending rates would fall following the intervention, a significant and persistent reduction would require continuous government bond purchases amounting to about 250 billion euro after 2 years, or $37 \%$ of all outstanding periphery bonds with maturities of one to three years. The ECB would thus become one of the major creditors of euro area periphery countries, a situation that might further blur the line between monetary and fiscal policy.

So far, only a few studies focusing on euro area member countries have analyzed the reaction of bank lending rates to changing government bond rates after the outbreak of the sovereign debt crisis at the beginning of 2010. Neri (2013) estimates autoregressive distributed lag (ADL) models to explore the responsiveness of bank lending rates to tensions in sovereign debt markets over the period 2003-2011 by using the seemingly unrelated regression (SUR) method. Sovereign risk is measured by means of the spread between the yields on government bonds and the 10-year swap rate of equal maturity. His findings depart from ours as he reports that the impact on bank lending rates in the euro area periphery countries arising from increasing government bond rates due to tightening sovereign risk has significantly raised over time. Moreover, he concludes that "if the system of equations [...] is estimated over the period 2003-2007 the parameters measuring the pass-through of changes in the sovereign spreads to bank lending rates in all the countries considered are not statistically different from zero. This is in accordance with the thesis that

\footnotetext{
${ }^{4}$ Note that we exclude Greece due to instability of government bond rate series, which is related to the Greek debt restructuring in March 2012.
} 
prior to the crisis government bond yields had little importance for banks' price setting policies for short-term loans" (Neri, 2013, p. 14). This finding is at odds with the view of the ECB, which justifies the OMT program by arguing that government bond markets "are very relevant in determining the financing conditions of banks" (European Central Bank, 2012a, p. 7).

Zoli (2013) estimates a VAR model for Italy to evaluate the reaction of bank lending rates to sovereign spreads over the period 2006-2012. Her findings suggest that changes in sovereign spreads quickly affect bank lending rates. Albertazzi, Ropele, Sene, and Signoretti (2012) provide similar results. However, a drawback of these studies is the assumption of model parameter stability over time since potential distortions that likely arose during the financial market turmoil in 2008 are neglected. Hristov, Hülsewig, and Wollmershäuser (2012a) show that bank lending rates in the periphery euro area member countries were significantly affected by the systematic increase in the volatility of structural shocks since 2008 and additionally that shocks particularly related to the financial crisis, such as loan supply shocks, became more relevant. The findings of Neri (2013) provide support for this result, at least by showing that the transmission of tensions in sovereign debt markets to bank lending rates has changed over time. Thus, the assumption of parameter stability seems doubtful. Therefore, in this study we employ a time-varying parameter VAR setup that allows us to account for dynamics of the pass-through from bond to loan markets.

The reminder of the paper is organized as follows. Section 2 outlines the TVPVAR model setup. We provide an overview of the model framework, introduce the data base and discuss the model specification strategy. In Section 3 we present our empirical results for the periphery euro area member countries. We discuss the implications of our results and provide a counterfactual policy experiment. Section 4 summarizes and concludes.

\section{TVP-VAR Model Setup}

\subsection{Model Framework}

We use TVP-VAR models for selected euro area periphery countries to explore the reaction of bank lending rates to shocks in government bond rates over time. We refer to Primiceri (2005), Nakajima (2011) and Nakajima, Kasuya, and Watanabe (2011) for a full-fledged discussion of the framework. ${ }^{5}$ Using a model with both time-

\footnotetext{
${ }^{5}$ Further studies using the same or a very similar approach are Canova and Ciccarelli (2009), Canova and Gambetti (2009), Koop, Leon-Gonzalez, and Strachan (2009), Sa, Towbin, and
} 
varying coefficient matrices and time-varying covariance matrices of the exogenous shocks has the advantage that the framework is flexible enough to cope with changes in the monetary transmission mechanism as well as with the huge distortions arising from crises, such as the financial crisis that erupted in 2008 and the sovereign debt crisis that started at the beginning of 2010 .

Consider the reduced form TVP-VAR model:

$$
Y_{t}=C_{t}+B_{1 t} Y_{t-1}+\cdots+B_{k t} Y_{t-k}+u_{t}, \quad t=k+1, \ldots, T
$$

where $Y_{t}$ is a $n \times 1$ vector of endogenous variables, $C_{t}$ is a $n \times 1$ vector of time varying intercepts, $B_{i t}$ are $n \times n$ matrices of time varying coefficients with $i=1, \ldots, k$ and $k$ equal to the number of lags, and $u_{t}$ is a $n \times 1$ vector of possibly correlated residuals.

Let $\Omega_{t}$ denote the covariance matrix of $u_{t}$, which can be decomposed as follows:

$$
\Omega_{t}=A_{t}^{-1} \Sigma_{t} A_{t}^{-1^{\prime}}
$$

where $A_{t}$ is a lower triangular matrix

$$
A_{t}=\left[\begin{array}{cccc}
1 & 0 & \ldots & 0 \\
\alpha_{21, t} & 1 & \ddots & \vdots \\
\vdots & \ddots & \ddots & 0 \\
\alpha_{n 1, t} & \ldots & \alpha_{n n-1, t} & 1
\end{array}\right]
$$

and the covariance matrix $\Sigma_{t}$ is diagonal

$$
\Sigma_{t}=\left[\begin{array}{cccc}
\sigma_{1 t} & 0 & \ldots & 0 \\
0 & \sigma_{2 t} & \ddots & \vdots \\
\vdots & \ddots & \ddots & 0 \\
0 & \ldots & 0 & \sigma_{n t}
\end{array}\right]
$$

Following Primiceri (2005) the structural shock is identified recursively via

$$
u_{t}=A_{t}^{-1} \Sigma_{t}^{\frac{1}{2}} \varepsilon_{t}
$$

and $\operatorname{Var}\left(\varepsilon_{t}\right)=I_{n}$. The TVP-VAR model (2.1) can be rewritten as:

$$
\begin{aligned}
Y_{t} & =X_{t}^{\prime} B_{t}+A_{t}^{-1} \Sigma_{t}^{\frac{1}{2}} \varepsilon_{t} \\
X_{t}^{\prime} & =I_{n} \otimes\left[1, Y_{t-1}^{\prime}, \ldots, Y_{t-k}^{\prime}\right],
\end{aligned}
$$

Wieladek (2011) and D'Agostino, Gambetti, and Giannone (2013) among others. 
where $B_{t}$ is a stacked vector containing all coefficients of the right hand side of (2.1) and $\otimes$ denotes the Kronecker product. The model parameters are assumed to follow a random walk process (Primiceri, 2005):

$$
\begin{aligned}
B_{t} & =B_{t-1}+\nu_{t} \\
\alpha_{t} & =\alpha_{t-1}+\zeta_{t} \\
\log \sigma_{t} & =\log \sigma_{t-1}+\eta_{t},
\end{aligned}
$$

where $\alpha_{t}$ denotes a stacked vector of the lower triangular elements in $A_{t}$ and $\sigma_{t}$ is the vector of the diagonal elements in $\Sigma_{t}$. The random-walk specification is used in most studies resorting to the TVP-VAR approach. All innovations in the model are assumed to be jointly normally distributed with variance-covariance matrix

$$
\operatorname{Var}\left(\left[\varepsilon_{t} \nu_{t} \zeta_{t} \eta_{t}\right]^{\prime}\right)=\left[\begin{array}{cccc}
I_{n} & 0 & 0 & 0 \\
0 & Q & 0 & 0 \\
0 & 0 & S & 0 \\
0 & 0 & 0 & W
\end{array}\right]
$$

Following Nakajima (2011), we further reduce the parameter space by assuming the covariance matrices $Q, S$ and $W$ to be diagonal.

\subsection{Data}

We employ monthly data for a number of euro area periphery countries covering the period 2003M1-2013M4. The countries include Ireland, Italy, Portugal and Spain. ${ }^{6}$ Since our analysis is aimed at elaborating the reaction of bank lending rates to changes in government bond rates we use a bivariate model $Y_{t}=\left[\mathrm{GBR}_{t} \mathrm{BLR}_{t}\right]^{\prime}$, where $\mathrm{GBR}_{t}$ denotes the government bond rate and $\mathrm{BLR}_{t}$ is the bank lending rate. The government bond rates are monthly averages, calculated from the FTSE Global Government Bond Indices with an average maturity of one to three years. The choice of maturities is related to the modalities of the OMT program according to which only the shorter part of the yield curve, with maturities between one and three years are considered (European Central Bank, 2012b). The series for the government bond rates are taken from Thomson Reuters DataStream. The bank lending rates refer to interest rates on new business loans to non-financial corporations (excluding revolving loans and overdrafts, convenience and extended credit card debt), with a maturity of up to one year (BLR-1Y) and over one year (BLR+1Y). The series are

\footnotetext{
${ }^{6}$ Recall that we exclude Greece due to instability of government bond rate series, which is related to the Greek debt restructuring in March 2012.
} 
taken from the ECB's harmonized MFI interest rate statistics.

In order to economize on computing time we refrained from estimating a TVPVAR model for every periphery euro area member country that would possibly be eligible for the OMT program. Instead, we calculated average interest rates for the periphery countries by using national nominal GDPs as weights. ${ }^{7}$

\subsection{Model Specification and Priors}

The TVP-VAR model setup leaves various degrees of freedom regarding the exact specification of the lag length considered and the informativeness of the priors for the degree of time-variation in the coefficient matrices and covariance matrices. This ambiguity makes a thorough model selection process particularly important. The lag length $k$ of each TVP-VAR model is set equal to 2 and is determined using the Schwarz information criterion, that is computed from a constant-parameters model estimated over the entire sample from 2003M1-2013M4. The priors for the diagonal elements of the hyperparameters $Q, S$ and $W$ are assumed to be distributed as (independent) inverse-Gamma while the priors for the initial states of the time varying VAR-parameters, $B_{0}, \alpha_{0}$ and $\log \sigma_{0}$, are chosen to be normal (see Primiceri, 2005; Nakajima, 2011, and others). In particular, we parameterize the prior distributions as recommended by Primiceri (2005):

$$
\begin{aligned}
B_{0} & \sim N\left(\hat{B}_{O L S}, 4 \cdot V\left(\hat{B}_{O L S}\right)\right), \\
\alpha_{0} & \sim N\left(\hat{\alpha}_{O L S}, 4 \cdot V\left(\hat{\alpha}_{O L S}\right)\right), \\
\log \sigma_{0} & \sim N\left(\log \hat{\sigma}_{O L S}, I_{n} \cdot 10\right), \\
\operatorname{diag}(Q) & \sim I G\left(k_{Q}^{2} \cdot 36 \cdot V\left(\hat{B}_{O L S}\right), 36\right), \\
\operatorname{diag}(S) & \sim I G\left(k_{S}^{2} \cdot 2 \cdot V\left(\hat{\alpha}_{O L S}\right), 2\right), \\
\operatorname{diag}(W) & \sim I G\left(k_{W}^{2}, 3 \cdot \operatorname{diag}\left(I_{n}\right)\right),
\end{aligned}
$$

where $\hat{B}_{O L S}, \hat{\alpha}_{O L S}$ and $\hat{\sigma}_{O L S}$ are the OLS-estimates of $B, A$ and $\sigma$ based on a time invariant VAR estimated on a training sample covering the first 36 months of the complete sample. $\operatorname{diag}(Q), \operatorname{diag}(S)$ and $\operatorname{diag}(W)$ denote the vectors containing the diagonal elements of the corresponding matrices. $V\left(\hat{B}_{O L S}\right)$ and $V\left(\hat{\alpha}_{O L S}\right)$ are the vectors containing the variances of $\hat{B}_{O L S}$ and $\hat{\alpha}_{O L S}$ obtained from the same OLS estimation. $B_{0}, \alpha_{0}$ and $\log \sigma_{0}$ and their corresponding variances are used as a starting values in the Carter-Kohn algorithm employed to infer the paths of $B_{t}$ and

\footnotetext{
${ }^{7}$ See Appendix A for further information on the time series and for a description of the respective country weights adopted.
} 
$\alpha_{t}$ and the independence Metropolis-Hastings algorithm used to compute the path of $\sigma_{t}{ }^{8}$

Since our sample is relatively short, the scaling parameters $k_{Q}, k_{S}$ and $k_{W}$ can have non-negligible effects on the estimated time variation in the VAR coefficients. Accordingly, caution is warranted when selecting values for these parameters. Since there are no economic reasons for preferring one $\left(k_{Q}, k_{S}, k_{W}\right)$ combination over another, we base our parametrization on a formal statistical criterion. In particular, we evaluate the marginal likelihood for our TVP-VAR model at each point of the three dimensional grid defined by $k_{Q}=\{0.005,0.01,0.025,0.05,0.075,0.100,0.125\}$, $k_{S}=\{0.001,0.01,0.05,0.1,0.5,1.0,2.0,4.0\}, k_{W}=\{0.05,0.10,0.25,0.5,1.0,2.0,5.0\}$ and choose the combination of $\left(k_{Q}, k_{S}, k_{W}\right)$ with the highest marginal likelihood. ${ }^{9}$

The posterior distributions as well as various statistics of interest are computed by means of a Markov Chain Monte Carlo (MCMC) algorithm described in Appendix B. We choose the number of Markov-Chain samples such that all Markov chains converge according to the Geweke criterion, ${ }^{10}$ using a burn-in rate of $20 \%$.

Tables 1 and 2 show the marginal likelihood of selected prior specifications. For the TVP-VAR model with short-term bank lending rates (BLR-1Y, see Table 1) the highest marginal likelihood is obtained when setting $\left(k_{Q}, k_{S}, k_{W}\right)$ equal to $(0.05,0.05,1.0)$, which henceforth will be our baseline specification. Since already small deviations in $k_{Q}$ and $k_{W}$ from the baseline values lead to noticeable decreases in the marginal likelihood, we are confident with the choice of these hyperparameters. By contrast, deviations of $k_{S}$ from 0.05 (keeping $k_{Q}$ and $k_{W}$ at their baseline values) only marginally deteriorates the marginal likelihood, which induces us to check the robustness of our empirical results with respect to alternative values for $k_{S}$ (equal to 1 and 0.01). ${ }^{11}$ The priors for the baseline TVP-VAR model with longterm bank lending rates (BLR+1Y, see Table 2$)$ are based on $\left(k_{Q}, k_{S}, k_{W}\right)$ equal to $(0.075,0.05,0.5)$. In contrast to the model with short-maturity loan rates, the prior specification for the TVP-VAR with long-maturity loan rates is more clear cut, as deviations from the baseline model along all three dimensions lead to strong decreases in the marginal likelihood.

In addition, it is important to note that for both models the use of a time-varying parameter set-up is confirmed by the data. If we choose hyperparameters which are much smaller than in our baseline specification (for instance $\left(k_{Q}, k_{S}, k_{W}\right)=$

\footnotetext{
${ }^{8}$ See Appendix B for details. Note, that since we resort to the independence Metropolis-Hastings algorithm, our estimation is immune to the problems described in DelNegro and Primiceri (2013).

${ }^{9}$ See Appendix $\mathrm{C}$ for details on the computation of the marginal likelihood.

${ }^{10}$ See Geweke (1994) for a description of the statistic.

${ }^{11}$ The two robustness checks are available from the authors upon request. The results that will be presented in the following Section do not depend on the choice of $k_{S}$.
} 
Table 1: Marginal likelihood of selected prior specifications (BLR-1Y)

\begin{tabular}{ccccccc}
\hline & & & \multicolumn{5}{c}{$k_{W}$} \\
$k_{Q}=0.10$ & $\mathbf{5 . 0}$ & $\mathbf{2 . 0}$ & $\mathbf{1 . 0}$ & $\mathbf{0 . 5}$ & $\mathbf{0 . 2 5}$ \\
\hline & $\mathbf{4 . 0 0 0}$ & -669.4 & -670.2 & -670.1 & -668.9 & -681.9 \\
& $\mathbf{1 . 0 0 0}$ & -678.7 & -676.4 & -669.3 & -667.5 & -682.9 \\
& $\mathbf{0 . 0 5 0}$ & -672.3 & -675.7 & -666.3 & -666.1 & -674.3 \\
& $\mathbf{0 . 0 1 0}$ & -690.9 & -672.0 & -666.1 & -666.1 & -674.2 \\
& $\mathbf{0 . 0 0 1}$ & -693.2 & -682.4 & -688.5 & -694.9 & -703.4 \\
\hline \multirow{4}{*}{$=0.05$} & $\mathbf{4 . 0 0 0}$ & -672.0 & -667.7 & -659.5 & -664.9 & -679.7 \\
& $\mathbf{0 . 0 5 0}$ & -674.4 & -669.3 & -656.3 & -665.1 & -677.4 \\
& $\mathbf{0 . 0 1 0}$ & -696.5 & -664.1 & -655.3 & -663.7 & -677.9 \\
& $\mathbf{0 . 0 0 1}$ & -683.0 & -682.2 & -686.4 & -696.5 & -713.6 \\
\hline & $\mathbf{4 . 0 0 0}$ & -688.2 & -668.6 & -664.1 & -671.7 & -686.6 \\
$k_{Q}=0.01$ & $\mathbf{1 . 0 0 0}$ & -685.5 & -668.1 & -657.8 & -672.9 & -684.4 \\
& $\mathbf{0 . 0 5 0}$ & -674.7 & -665.9 & -658.4 & -671.8 & -684.0 \\
& $\mathbf{0 . 0 1 0}$ & -686.3 & -665.9 & -657.9 & -671.9 & -684.2 \\
& $\mathbf{0 . 0 0 1}$ & -686.0 & -684.5 & -687.0 & -699.4 & -711.7 \\
\hline
\end{tabular}

Table 2: Marginal likelihood of selected prior specifications (BLR+1Y)

\begin{tabular}{|c|c|c|c|c|c|c|}
\hline & $k_{S}$ & 5.0 & 2.0 & $\begin{array}{c}k_{W} \\
\mathbf{1 . 0}\end{array}$ & 0.5 & 0.25 \\
\hline \multirow{5}{*}{$k_{Q}=0.100$} & 4.000 & -751.4 & -746.5 & -735.9 & -737.6 & -748.2 \\
\hline & 1.000 & -758.3 & -740.7 & -729.2 & -730.8 & -746.0 \\
\hline & 0.500 & -746.5 & -747.5 & -727.8 & -736.3 & -748.7 \\
\hline & 0.050 & -756.6 & -736.6 & -732.7 & -734.4 & -752.8 \\
\hline & 0.001 & -758.4 & -755.5 & -752.9 & -743.5 & -752.6 \\
\hline \multirow{5}{*}{$k_{Q}=0.075$} & 4.000 & -752.9 & -743.8 & -727.7 & -739.2 & -753.5 \\
\hline & 1.000 & -745.5 & -739.1 & -736.2 & -731.5 & -745.9 \\
\hline & 0.500 & -749.8 & -735.5 & -738.4 & -731.7 & -746.0 \\
\hline & 0.050 & -744.5 & -741.5 & -729.1 & -722.0 & -747.2 \\
\hline & 0.001 & -766.1 & -749.7 & -753.4 & -744.9 & -747.6 \\
\hline \multirow{5}{*}{$k_{Q}=0.050$} & 4.000 & -749.7 & -738.3 & -728.4 & -727.9 & -749.0 \\
\hline & 1.000 & -744.4 & -732.1 & -733.2 & -731.8 & -744.9 \\
\hline & 0.500 & -745.7 & -742.3 & -725.1 & -730.6 & -745.6 \\
\hline & 0.050 & -747.7 & -737.1 & -725.8 & -732.8 & -744.5 \\
\hline & 0.001 & -759.2 & -761.9 & -748.8 & -747.3 & -753.5 \\
\hline
\end{tabular}


$(0.01,0.001,0.25)$ for the model using short-term bank lending rates and

$\left(k_{Q}, k_{S}, k_{W}\right)=(0.05,0.001,0.25)$ for the model using long-term bank lending rates), the corresponding marginal likelihoods decrease (by $9 \%$ for BLR-1Y and by $4 \%$ for BLR+1Y). Therefore, a TVP-VAR model appears preferable to a standard VAR model with constant parameters.

\section{Empirical Results}

\subsection{Impulse Response Functions}

Figure 1 displays the time profile of the median impulse responses of the bank lending rate to a shock in the government bond rate. The $\mathrm{z}$-axis measures the deviation of the bank lending rate from its steady state in percentage points, the $\mathrm{x}$-axis displays the point of time on the basis of which the impulse response functions have been computed, and the $\mathrm{y}$-axis shows the periods following the shock. Since for the estimation of the TVP-VAR model a training sample of 36 months and a lag length of two was chosen the first impulse response function is obtained for 2006M3. For the computation of the impulse responses we use the model parameters estimated for a specific point in time (as shown on the $\mathrm{x}$-axis) and assume that these parameters remain constant over the impulse horizon (y-axis). In order to isolate changes in the propagation of the shock from changes in the volatility of the shocks over time, the impulse responses are constructed such that in each month the bond rate shock is normalized to -1 percentage point. Figure 2 displays the same impulse responses by showing an individual graph for each horizon ranging from the impact period (horizon 0) to 11 months after the shock. Each panel shows the mean response at a particular horizon as well as the corresponding $90 \%$ confidence interval (shaded area) based on the draws of the MCMC algorithm.

The graphs show that bank lending rates immediately fall after a 1 percentage point drop of the government bond rate, but their reaction is limited. While the impact reaction of bank lending rates turns out to be rather stable over time, with an average reduction of BLR-1Y (BLR+1Y) by $0.06(0.22)$ percentage points, the responses several months after the occurrence of the shock exhibit a pronounced time-varying pattern.

In the period up to mid-2008 the pass-through from government bond rates to bank lending rates is strongest, amounting to approximately $40 \%$ (60\%) of the initial bond rate reduction for BLR-1Y (BLR+1Y) after around 7 (4) months. While the response of BLR-1Y remained on that level until the end of the response horizon, $\mathrm{BLR}+1 \mathrm{Y}$ declined by about 0.2 percentage points. Interestingly, the beginning of the 
Figure 1: Bank Lending Rate Response to a -1 Percentage Point Government Bond Rate Shock

Short-term bank lending rate (BLR-1Y)

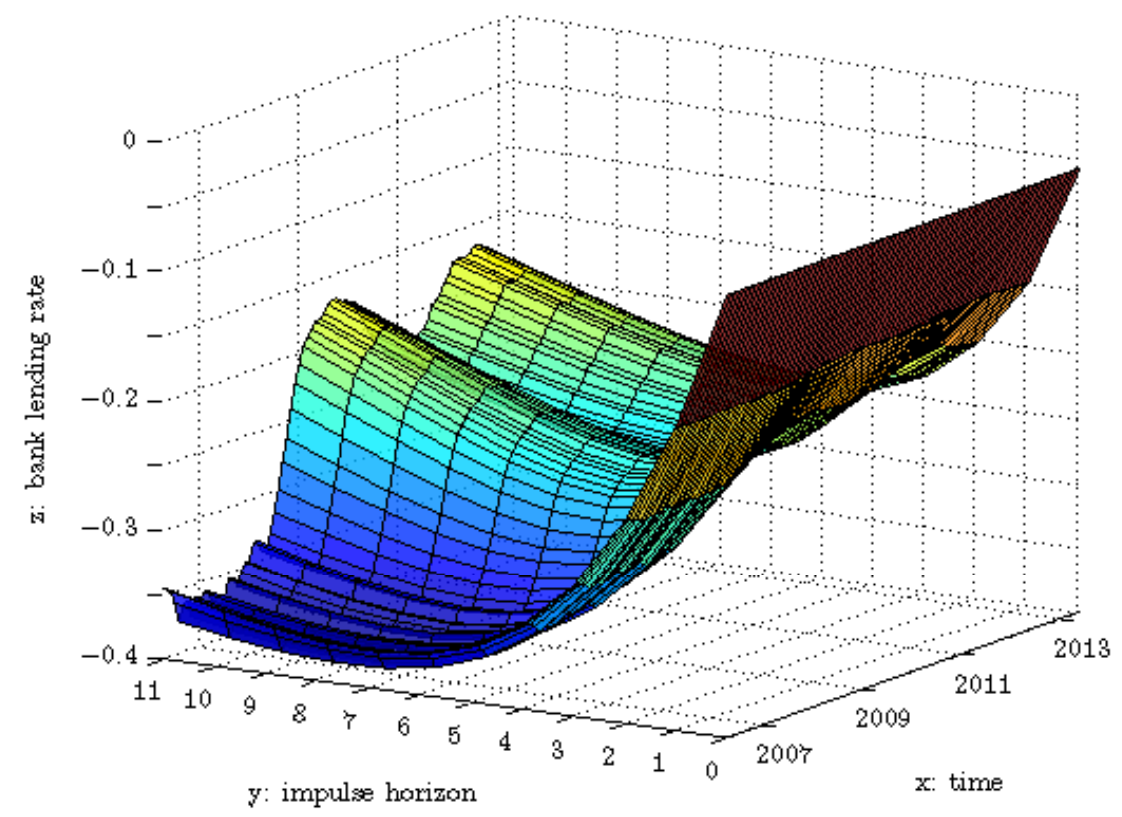

Long-term bank lending rate $(B L R+1 Y)$

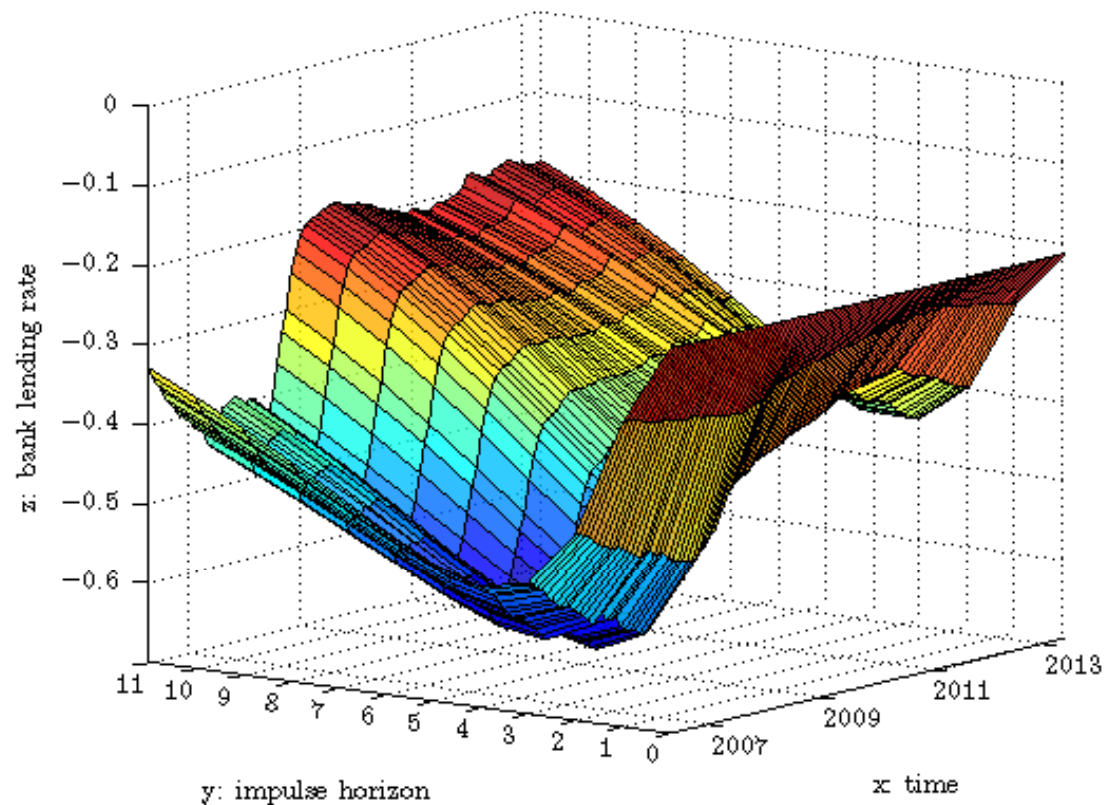

Notes: The graph plots the time-varying median response of the bank lending rate (as percentage point deviation from its steady state) to a -1 percentage point shock of the government bond rate equation over the 12 months following the shock. 
Figure 2: Bank Lending Rate Response to a -1 Percentage Point Government Bond Rate Shock

Short-term bank lending rate (BLR-1Y)
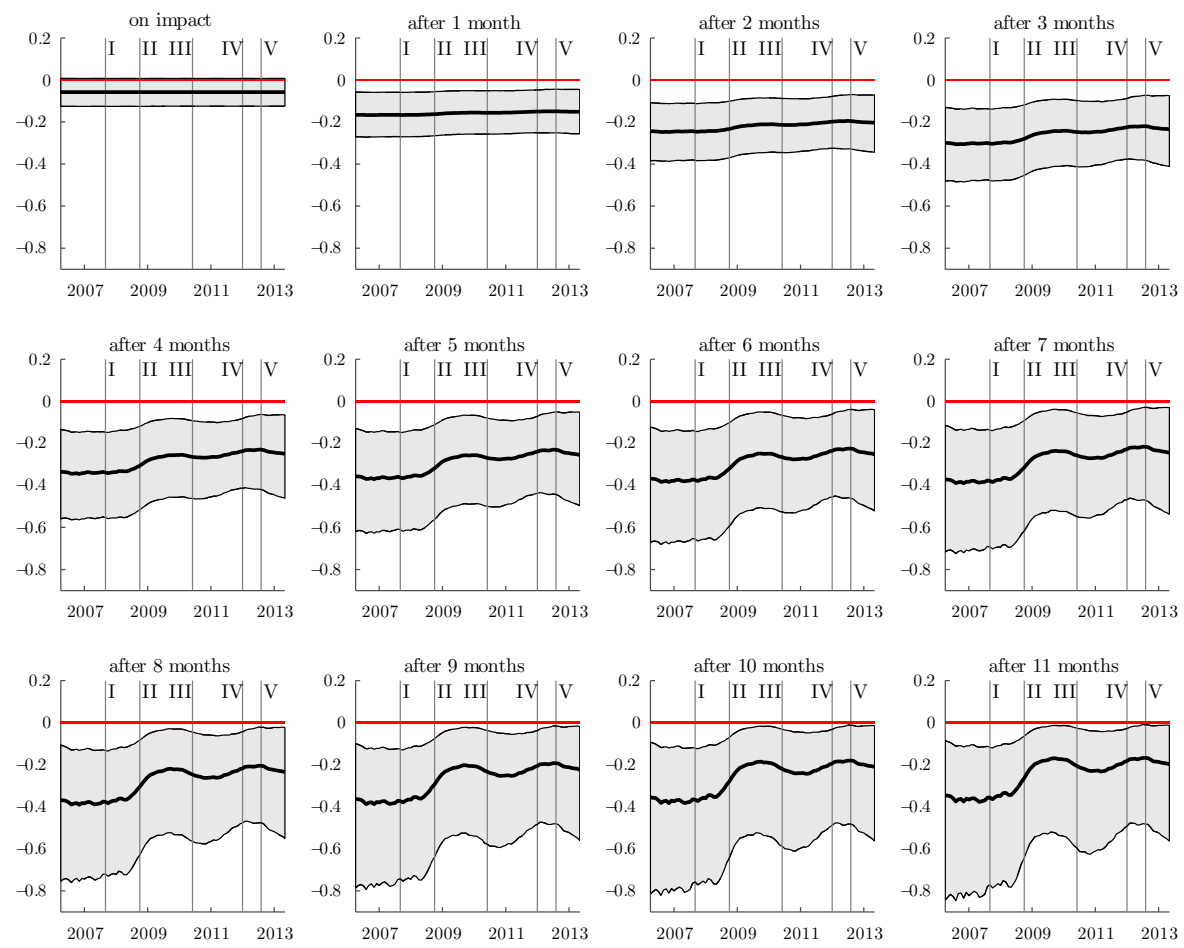

Long-term bank lending rate $(\mathrm{BLR}+1 \mathrm{Y})$
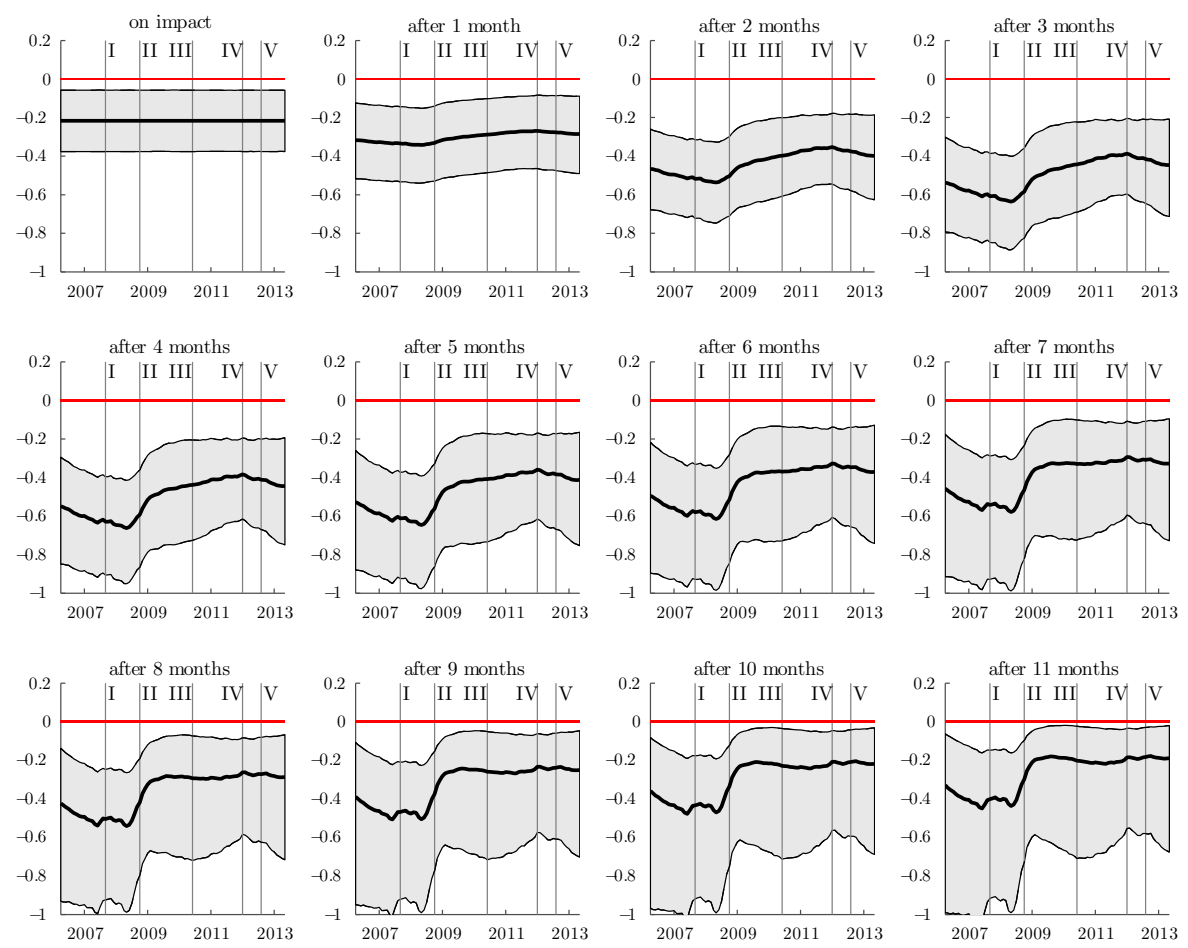

Notes: For each horizon the graph plots the response of the bank lending rate (as percentage point deviation from its steady state) to a -1 percentage point shock of the government bond rate equation. The bold line is the median response; the shaded areas are the related $90 \%$ confidence intervals. The vertical lines enumerated by I to $\mathrm{V}$ mark important events occurring during the euro crisis (see main text for further details). 
financial crisis in the summer of 2007 (vertical line I in Figure 2), when interbankmarket credit spreads started to increase and when, as a consequence, the ECB adopted its first quantitative measures by offering a number of additional 3-monthLTROs, hasn't had any impact yet on the transmission of government bond rates on bank lending rates.

A quantitatively important change in the pass-through relationship was observed around September 2008, when the investment bank Lehman Brothers went bankrupt and when the ECB started to vigorously cut policy rates and to adopt its full allotment policy (vertical line II in Figure 2). The maximum fall in bank lending rates following the -1 percentage point shock of the government bond rate was substantially smaller thereafter and only reached about two thirds of the maximum pre-crisis decline $(0.25$ (0.40) percentage point reduction after about five (three) months in the model with BLR-1Y (BLR+1Y)); after one year the response even halved compared to the pre-crisis period. Thus, the world financial crisis marked a pronounced structural break in the transmission of government bond rates on bank lending rates.

The burgeoning euro crisis, which gained momentum in May 2010 (vertical line III in Figure 2) when government bond spreads of the euro area periphery countries sharply increased and when the ECB launched its Securities Markets Program (i.e. the outright purchase of government bonds from the periphery countries), did not have any notable impact on the link between government bond rates and bank lending rates, which continued to remain weak. The massive interventions of the ECB by the end of 2011, when it provided two long-term refinancing operations with full allotment and a maturity of 3 years each (vertical line IV in Figure 2) and the ECB's announcement of the OMT program in the summer of 2012 (vertical line $\mathrm{V}$ in Figure 2) did not fundamentally change this result. If anything at all, a slight increase in the pass-through can be observed. However, compared to the pre-crisis period the response of bank lending rates to shocks of the government bond rate remained substantially weaker.

Identifying the reasons that have made the bank lending rates in the periphery countries less sensitive to changes in government bond rates in the period after late-2008 is beyond the scope of the paper, since our empirical model only reflects the correlation between these two interest rates. One of the causes might have been that those economies were hit by a sequence of adverse macroeconomic shocks reducing the average quality of borrowers and leading to a pronounced increase in non-performing loans thereby deteriorating banks' capital positions. As a consequence, banks could have altered their loan-rate setting behavior, which, in turn, could have triggered a decoupling of bank loan rates from movements in sovereign 
bond yields. For example, even though government bond rates decreased since mid 2012, the need to rebuild capital positions might have forced banks to contract loan supply, thus, inducing a persistent upward pressure on loan rates. The latter might have also remained elevated due to banks demanding a compensation for the higher level of borrowers' riskiness perceived during the euro crisis. In addition, the reluctance of banks to extend credit to the private sector could have also been the result of a sequence of adverse loan supply shocks that are typically characterized by an increase in interest rate spreads (Hristov, Hülsewig, and Wollmershäuser, 2012b).

\subsection{Stochastic Volatilities}

Instead of improving the transmission of monetary impulses by restoring a stronger link between government bond rates and bank lending rates, our estimates reveal that the main effect of the ECB's unconventional measures was a significant reduction of the uncertainty on government bond markets of the periphery countries. Figure 3 shows that the increase in the estimated stochastic volatility of the government bond rate, which can be observed since the summer of 2007 and which accelerated since May 2010, started to decline significantly with the ECB's liquidity injection by the end of 2011 .

\subsection{Policy Experiment}

As shown above the pass-through from government bond to bank lending rates was significantly attenuated in the euro area periphery countries in the wake of financial and sovereign crises. However, for policy makers it is important to understand both, the qualitative effects of the impaired pass-through as well as its quantitative implications. To illustrate the latter, we consider the following out-of-sample-simulation. We assume that in May 2013, i.e. the month following the end of our sample, the ECB would have started buying periphery government bonds via the OMT program. The size of the interventions, which enter as shocks to the government bond rate equation in the TVP-VAR model, is chosen to ensure that the corresponding bond rates immediately drop to the level of the core government bond yield observed in April 2013. ${ }^{12}$ Furthermore, the exercise is performed under the assumption that the model parameters remain constant at the level estimated either in March 2006

\footnotetext{
${ }^{12} \mathrm{Up}$ to now it is not clear whether the ECB, in case the OMT program has to be activated, will predetermine the amounts, the timing and the duration of government bond purchases. We assume that, similar to the Securities Markets Program (SMP) adopted in early 2010, the precise future path of OMTs will remain uncertain. In this case, repeated shocks to the government bond rate equation represent a valid approximation of OMTs interventions.
} 
Figure 3: Stochastic Volatilities

Short-term bank lending rate (BLR-1Y)
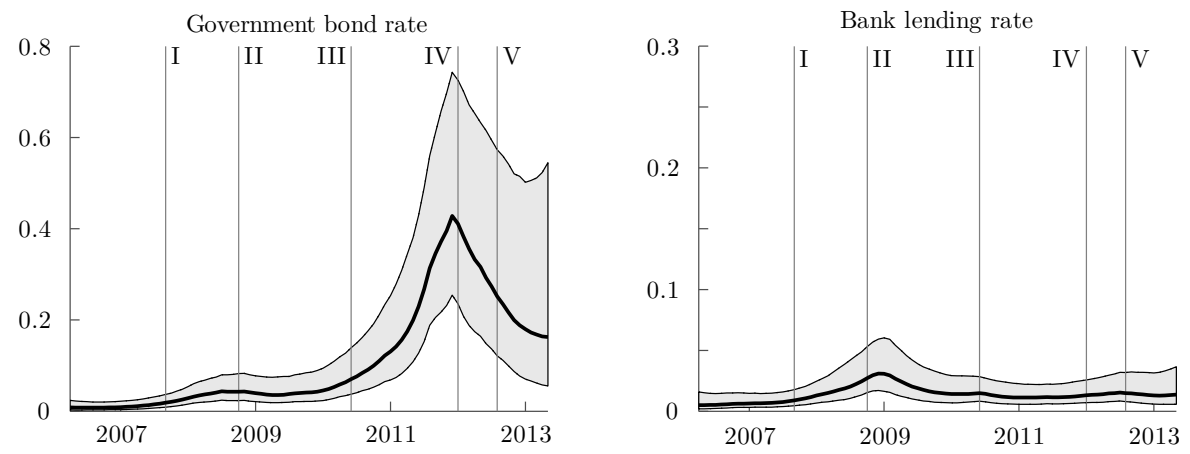

Long-term bank lending rate $(B L R+1 Y)$
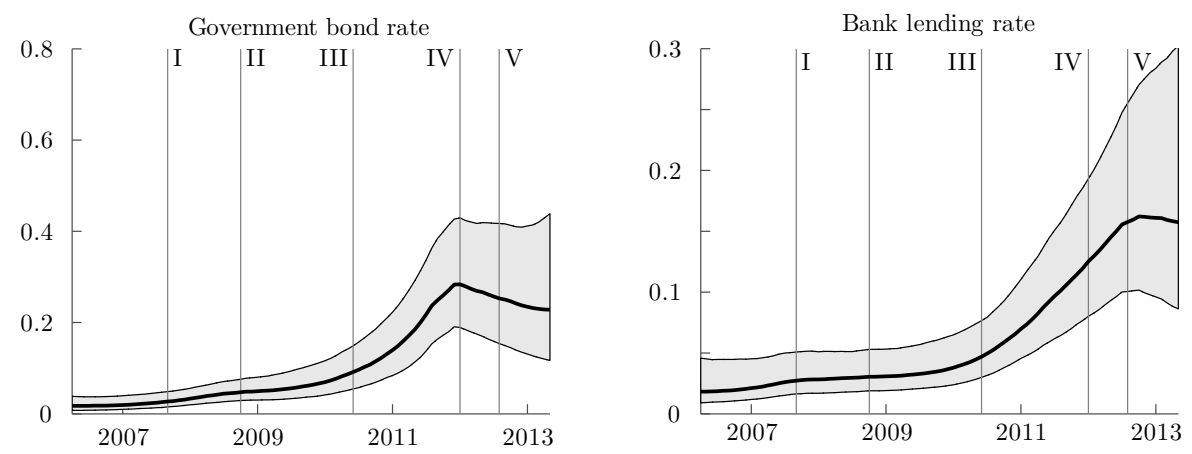

Notes: The graph plots the estimated stochastic volatilities $\hat{\sigma}_{t}$. The bold line is the median over all draws of the MCMC algorithm; the shaded areas are the related $90 \%$ confidence intervals. The vertical lines enumerated by I to $\mathrm{V}$ mark important events occurring during the euro crisis.

(pre-crisis parametrization) or in April 2013 (crisis parametrization).

We address the following two questions: First, how would periphery bank lending rates have responded to such an intervention by the ECB in the government bond market? And second, how large would be such an intervention by historical standards? Figure 4 shows the results of the counterfactual simulation. The upper two graphs refer to the TVP-VAR model with short-term bank lending rates (BLR-1Y) as endogenous variable using both, the pre-crisis parametrization and crisis parametrization. The lower two graphs show the same simulation for the model with long-term bank lending rates (BLR+1Y).

To answer the first question the left column of Figure 4 shows how bank lending rates respond to the immediate and permanent reduction in periphery government bond rates to the average level of government bond rates in the core countries, which was close to zero percent in April 2013. The decrease of the periphery government bond rate of about 1.8 percentage points has a strong initial impact on bank lending rates, but this effects fades off quickly over time. While in the case of BLR-1Y the 
Figure 4: Simulation of an ECB Intervention
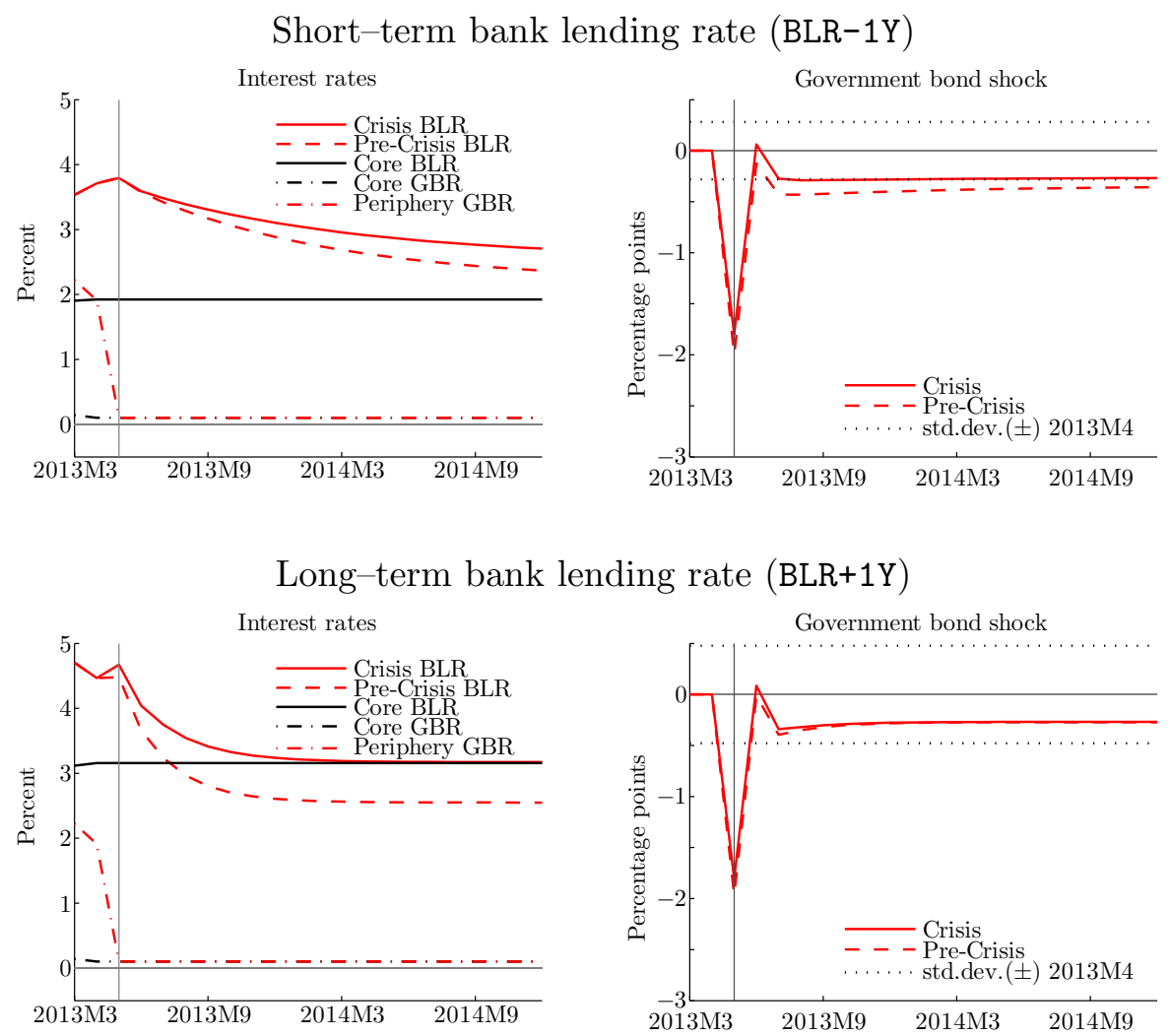

Notes: The simulation of the pre-crisis model uses the estimated coefficients for 2006M3, while the simulation of the crisis model is derived from the estimates for 2013M4. In the counterfactual, the ECB pushes the periphery bond rates instantaneously and permanently to the level of the core countries, which was observed in April 2013.

policy intervention does not succeed in eliminating the spread between periphery and core bank lending rates, it seems to be more effective in the case of BLR+1Y, where the policy intervention is able to reduce bank lending rates to core levels after 12 months. For both lending maturities the pass-through from government bond rates to bank lending rates was strongly attenuated during the crisis period. The policy intervention would reduce BLR-1Y (BLR+1Y) by $1.3(1.9)$ percentage points after one and a half year before the crisis, but only by $1.0(1.3)$ percentage points using the crisis parametrization. This corresponds to an attenuation of the passthrough of $25 \%$ (32\%). The weak transmission involves high perils for the ECB, as any economically important impact on bank lending rates would require huge exposure to periphery countries' risks in the ECB's balance sheet.

To see this more clearly we turn to the second question which addresses the size of the required ECB intervention by historical standards. The right column in Figure 4 plots the sequence of shocks to the government bond rate equation of the TVP-VAR model, which is necessary to permanently bring down the sovereign bond 
yield of the periphery to the desired level. Following a very strong intervention in 2013M5, which would have an immediate impact on bond rates of -1.8 percentage points in both models, the intervention intensity would stabilize from $2013 \mathrm{M} 7$ on at a permanent level of around -0.3 percentage points per month. That is to say that the ECB would have to continuously buy government bonds of the periphery countries. One way to assess the magnitude of these interventions is to relate them to the average size of the government bond rate shock observed in the past. ${ }^{13}$ The latest estimated standard deviation is shown as a dotted horizontal line in each graph on the right-hand side of Figure 4. This comparison shows that in particular the initial intervention would have to be four to five times larger than the average size of the shocks in our empirical model. While the subsequent interventions would have to be much smaller in size, equal to or, in the case of the model with BLR+1Y, even smaller than the empirical average, the fact that these interventions have to be permanent implies a sizable cumulated intervention volume.

An alternative way to address the second question and to assess the magnitude of the interventions required under the OMT program is to present figures on the related euro amount of government bond purchases. For this purpose we draw on the empirical results of Eser and Schwaab (2013) who estimate the elasticities of periphery government bond rates with respect to the ECB's government bond purchases undertaken within the Securities Markets Program (SMP). For our policy experiment we assume that the corresponding elasticities under the OMT program would be the same as under the SMP. ${ }^{14}$ While at first glance there are some similarities between the SMP and the OMT program, the use of the elasticities from the SMP suffers from al least two shortcomings. First, the average maturity of the bonds purchased under the SMP is longer than what has been announced by the ECB for OMTs. ${ }^{15}$ Thus, if the liquidty of the government bond markets for shorter

\footnotetext{
${ }^{13}$ The average size of the shock corresponds to its standard deviation which can derived from Figure 3 by simply taking the square root of the estimated volatilities. According to our estimates the average shock size in the model with BLR-1Y (BLR+1Y) as endogenous variable steadily increased from $\pm 0.09(0.13)$ percentage points in March 2006 to $\pm 0.66(0.53)$ percentage points in November 2011, and since then it fell to $\pm 0.40(0.48)$ percentage points in April 2013.

${ }^{14}$ The authors find that for Spain, Ireland, Italy and Portugal the impact of a one billion government bond purchase on bond yields with a maturity of five years has been about -0.06 percentage points, -0.02 percentage points, -0.01 percentage points and -0.09 percentage points, respectively. The numbers represent means over the point estimates derived from eight model specifications (see Eser and Schwaab, 2013, p.17). To make their results consistent with our methodology we compute the average government bond rate elasticity of the periphery by weighting the country-specific elasticities with their nominal GDP (as measured in the second quarter of 2013). We find that a one billion euro periphery bond purchase under the SMP reduced the periphery government bond rates by -0.03 percentage points. This result is robust to using alternative weights (such as government debt market size) for computing the periphery average.

${ }^{15}$ At the end of 2012 , i.e. one and a half years after the start of the SMP, the average maturity
} 
maturities deviates from the maturities acquired under the SMP, elasticities will change. Second, it is not clear whether the modalities of the interventions of the ECB under the OMT programm will be same as under the SMP. ${ }^{16}$ Therefore, the results presented below should be interpreted cautiously.

Figure 5 compares the euro amounts spent under the SMP to the required euro amounts for our policy experiment. For consistency, the SMP data only includes Spain, Ireland, Italy and Portugal. ${ }^{17}$ The SMP started smoothly in May 2010 with only small purchases of Irish and Portuguese bonds for the first 10 months (until February 2011) up to a volume of about 37 billion euro. It was only in August 2011 that the SMP took off sharply by additionally intervening in Spanish and Italian sovereign bond markets. The SMP was officially terminated in September 2012, but already after January 2012 no significant amounts of new bonds were acquired. At that time the ECB had bought periphery bonds worth about 182 billion euro. Despite this huge intervention the portfolio acquired under the SMP would be dwarfed by any economically meaningful intervention under the OMT program. Our policy experiment, in which the ECB reduces periphery government bond rates immediately and for ever, would require an initial purchase of about 60 billion euro and subsequent monthly purchases of about 9.3 billion euro. ${ }^{18}$ Thus, after 24 months the ECB would have accumulated a stock of periphery bonds worth about 250 billion euro, more than $10 \%$ of total euro area GDP and about $37 \%$ of all outstanding periphery bonds with maturities of one to three years. ${ }^{19}$ But, as Figure 4 shows, even this unprecedented intervention would not suffice to close the spread between core and periphery short-term (BLR-1Y) lending rates while regarding the long-term lending rates (BLR+1Y) it would only succeed in doing so after one year.

\footnotetext{
of the ECB's government bond portfolio was 4.3 years (European Central Bank, 2013).

${ }^{16}$ Eser and Schwaab (2013) report two types of elasticities - announcement-day elasticities for the first interventions under the SMP and pure intervention elasticities for the interventions following the announcement day. The former are substantially larger as they reflect a combination of the pure intervention effect and the announcement effect. Since the OMT program is already announced, we resort to the second type of elasticities measuring the pure intervention effect. According to Eser and Schwaab (2013) these elasticities are relevant for repeated, but non-predetermined bond purchases within an already open program.

${ }^{17}$ We are grateful to Michiel de Pooter for sharing his data with us (see De Pooter, Martin, and Pruitt, 2013, Figure 3).

${ }^{18}$ The required intervention volume is the same for both model specifications, i.e. the model with both, BLR-1Y and BLR+1Y as endogenous variable.

${ }^{19}$ Amounts as of April 2013.
} 
Figure 5: Cumulated intervention volumes

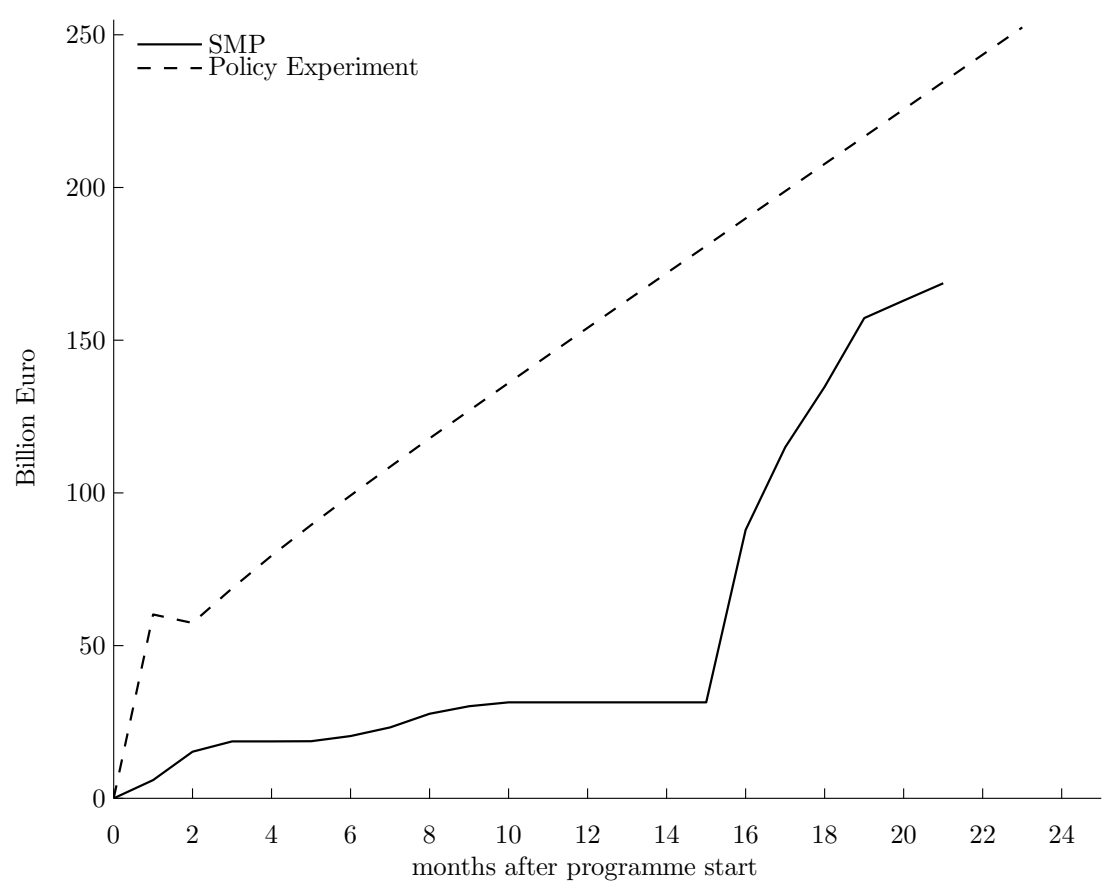

Notes: The graph plots the cumulated intervention volumes under the ECB's SMP (excluding purchases of Greek government bonds) and those resulting from our policy experiment for 24 months after the first intervention. The SMP was implemented in May 2010 and was officially terminated in September 2012. However, the last quantitatively significant interventions were carried out in January 2012, i.e. 21 months after the official kick-off of the program. The volumes of government bonds purchased under the SMP were provided by De Pooter, Martin, and Pruitt (2013).

\section{Conclusion}

This paper has explored the potential effectiveness of the ECB's OMT program in restoring the monetary transmission mechanism. Using TVP-VAR models for a number of euro area periphery countries we have analyzed the response of bank lending rates to movements in government bond rates.

According to the ECB, the necessity of the OMT program is related to the point of view that the transmission of monetary policy in the euro area is severely impaired due to widely divergent borrowing costs across member countries. A major source of impairment is the fear that one of the euro area periphery member countries or more - could exit the euro, which has driven up risk premia on sovereign bonds. Since government bond markets play an important role for the determination of bank lending rates, basically because sovereign bond rates serve directly as a benchmark for the pricing of bank loans, the government bond market turmoil has affected bank lending conditions. As a consequence bank lending rates in the euro area periphery countries have remained on a relatively high level, despite the massive cut of policy 
rates. The OMT program is officially considered as a sufficient means for restoring the transmission mechanism of monetary policy (European Central Bank, 2012a).

However, the results of our analysis cast serious doubts on the potential effectiveness of the OMT program in safeguarding an appropriate monetary policy transmission as we only find a minor reaction of bank lending rates to movements in sovereign bond rates. While bank lending rates in the euro area periphery member countries had already reacted sluggishly to changes in sovereign bond rates before the outbreak of the government bond market turmoil in 2010, their response to changes in sovereign bond rates has further weakened significantly thereafter. Therefore, the theoretical underpinning of the OMT program, namely the view that the high bank lending rates in the euro area periphery are above all determined by the high government bond rates, is hardly supported empirically.

Although the announcement of the ECB's OMT program has lowered the borrowing costs for sovereigns in the euro area periphery countries, our findings suggest that a significant reduction of bank lending rates would require continuous government bond purchases amounting to about 250 billion euro after 2 years, or $37 \%$ of all outstanding periphery bonds with maturities of one to three years. However, continuous purchases of bonds issued by the peripheral sovereigns would come along with a number of serious problems like undermining the incentives for governments to impose structural reforms, violating the prohibition to monetize public debt, or exposing the ECB to huge balance sheet risks, which in turn might threaten the political independence of the monetary authority. As the implementation OMTs would go too far into the terrain of fiscal policy, we conclude that it would rather damage the reputation of the ECB instead of contributing to effectively relax bank lending conditions. In our view the insensitivity of periphery bank lending rates to monetary impulses is the result of a severe undercapitalization of many commercial banks in those economies. Instead of hoping for monetary policy interventions, appropriate and timely measures by European governments should be implemented. Such measures should be aimed at restructuring insolvent financial institutions by freeing balance sheets from doubtful loans and by recapitalizing the banking sector. 


\section{References}

Albertazzi, U., T. Ropele, G. Sene, And F. M. Signoretti (2012): "The Impact of the Sovereign Debt Crisis on the Activity of Italian Banks," Questioni di Economia e Finanza (Occasional Papers) 133, Bank of Italy, Economic Research and International Relations Area.

Aristei, D., And M. Gallo (2012): "Interest Rate Pass-Through in the Euro Area during the Financial Crisis: a Multivariate Regime-Switching Approach," Quaderni del Dipartimento di Economia, Finanza e Statistica 107/2012, Universit? di Perugia, Dipartimento Economia, Finanza e Statistica.

Blot, C., and F. Labondance (2013): "Business Lending Rate Pass-Through in the Eurozone: Monetary Policy Transmission during the Boom and since the Financial Crash," Economics Bulletin, 33(2), 973-985.

Canova, F., And M. Ciccarelli (2009): "Estimating Multicountry VAR Models," International Economic Review, 50(3), 929-959.

Canova, F., And L. Gambetti (2009): "Structural Changes in the US Economy: Is there a Role for Monetary Policy?," Journal of Economic Dynamics and Control, 33(2), 477-490.

D'Agostino, A., L. Gambetti, And D. Giannone (2013): "Macroeconomic Forecasting and Structural Change," Journal of Applied Econometrics, 28(1), 82-101.

De Grauwe, P. (2013): "The European Central Bank as Lender of Last Resort in the Government Bond Markets," CESifo Economic Studies, 59(3), 520-535.

De Pooter, M., R. F. Martin, and S. Pruitt (2013): "The Liquidity Effects of Official Bond Market Intervention," Discussion paper, Federal Reserve Board of Governors.

Delnegro, M., and G. Primiceri (2013): "Time-varying Structural Vector Autoregressions and Monetary Policy: A Corrigendum," Staff Reports 619, Federal Reserve Bank of New York.

Deutsche Bundesbank (2012): "Stellungnahme gegenüber dem Bundesverfassungsgericht zu den Verfahren mit den Az. 2 BvR 1390/12, 2 BvR 1421/12, 2 BvR 1439/12, 2 BvR 1824/12, 2 BvE 6/12," Expertise, Deutsche Bundesbank.

Eser, F., And B. SchwaAb (2013): "Assessing Asset Purchases within the ECB's Securities Markets Programme," Working Paper Series 1587, European Central Bank.

European Central Bank (2012a): "Editorial," Monthly Bulletin, September, 5-11.

— (2012b): "Editorial," Monthly Bulletin, October, 5-7.

(2013): "Details on Securities Holdings Acquired under the Securities Markets Programme," Press Release, 21 February.

Fratzscher, M. (2013): "Zum wärungspolitischen Mandat der EZB und möglichen Auswirkungen von Maßnahmen der EZB auf die nationalen Haushalte," Wirtschaftsdienst, 93(7), 445-451. 
Fratzscher, M., F. Giavazzi, R. Portes, B. Weder di Mauro, and C. Wyplosz (2013): "A Call for Support for the European Central Bank's OMT Programme," https://berlinoeconomicus.diw.de/monetarypolicy/.

Fuest, C. (2013): "EZB in der Grauzone zwischen Geld-und Fiskalpolitik," Wirtschaftsdienst, 93(7), 440-442.

Gelfand, A., And D. Dey (1994): "Bayesian Model Choice: Asymptotics and Exact Calculations," Journal of the Royal Statistical Society. Series B, 56(3), 501-514.

Geweke, J. (1994): "Priors for Macroeconomic Time Series and Their Application," Econometric Theory, 10(3-4), 609-632.

Giavazzi, F., R. Portes, B. Weder di Mauro, and C. Wyplosz (2013): "The Wisdom of Karlsruhe: The OMT Court Case should be dismissed," VOX: Research-based policy analysis and commentary from leading economists, http://www.voxeu.org/article/wisdom-karlsruhe-omt-court-case-should-be-dismissed.

Hristov, N., O. Hülsewig, And T. Wollmershäuser (2012a): "The Interest Rate Pass-Through in the Euro Area During the Global Financial Crisis," CESifo Working Paper Series 3964, CESifo Group Munich.

(2012b): "Loan Supply Shocks during the Financial Crisis: Evidence for the Euro Area," Journal of International Money and Finance, 31(3), 569-592.

Konrad, K. (2013): "Haftungsrisiken und Fehlanreize aus ESM und OMT-Programm," Wirtschaftsdienst, 93(7), 431-439.

Koop, G., R. Leon-Gonzalez, and R. W. Strachan (2009): "On the Evolution of the Monetary Policy Transmission Mechanism," Journal of Economic Dynamics and Control, 33(4), 997-1017.

NAKajIma, J. (2011): "Time-Varying Parameter VAR Model with Stochastic Volatility: An Overview of Methodology and Empirical Applications," IMES Discussion Paper Series 11-E-09, Institute for Monetary and Economic Studies, Bank of Japan.

Nakajima, J., M. Kasuya, And T. Watanabe (2011): "Bayesian Analysis of Timevarying Parameter Vector Autoregressive Model for the Japanese Economy and Monetary Policy," Journal of the Japanese and International Economies, 25(3), 225-245.

NeRI, S. (2013): "The Impact of the Sovereign Debt Crisis on Bank Lending Rates in the Euro Area," Questioni di Economia e Finanza (Occasional Papers) 170, Bank of Italy, Economic Research and International Relations Area.

Petch, T. (2013): "The Compatibility of Outright Monetary Transactions with EU Law," Law and Financial Markets Review, 7(1), 13-21.

Primiceri, G. E. (2005): "Time Varying Structural Vector Autoregressions and Monetary Policy," Review of Economic Studies, 72(3), 821-852.

SA, F., P. Towbin, And T. Wieladek (2011): "Low Interest Rates and Housing Booms: The Role of Capital Inflows, Monetary Policy and Financial Innovation," Globalization and Monetary Policy Institute Working Paper 79, Federal Reserve Bank of Dallas. 
Siekmann, H., AND V. Wieland (2013): "The European Central Bank's Outright Monetary Transactions and the Federal Constitutional Court of Germany," Working Paper Series 71, Institute for Monetary and Financial Stability Goethe University Frankfurt am Main.

SinN, H.-W. (2013): "Verantwortung der Staaten und Notenbanken in der Eurokrise," Wirtschaftsdienst, 93(7), 451-454.

Uhlig, H. (2013): "Outright Monetary Transactions und Target2," Wirtschaftsdienst, 93(7), 443-444.

Weidmann, J. (2013): "Eingangserklärung anlässlich der mündlichen Verhandlung im Hauptsacheverfahren ESM/EZB," http://www.bundesbank.de/Redaktion/DE/Kurzmeldungen/Stellungnahmen.html.

Zoli, E. (2013): "Italian Sovereign Spreads: Their Determinants and Pass-through to Bank Funding Costs and Lending Conditions," IMF Working Paper WP/13/84, International Monetary Fund. 


\section{Appendix}

\section{A Data}

The bank lending rates refer to interest rates on new business loans to non-financial corporations (excluding revolving loans and overdrafts, convenience and extended credit card debt), with a maturity of up to one year (BLR-1Y) and over one year $(B L R+1 Y)$. The monthly series, which are taken from the ECB's harmonized MFI interest rate statistics, cover the period 2003M1-2013M4. The data code is

MIR.M.XX.B.A2A.F.R.A.2240.EUR.N for the short-term bank lending rates and MIR.M.XX.B.A2A.K.R.A.2240.EUR.N for the long-term bank lending rates; XX is the country acronym.

The government bond rates are monthly averages, calculated from daily FTSE Global Government Bond Indices with an average maturity of one to three years. The series are taken from the Thompson Reuters DataStream database. We use the series RGXX1T3(RY), where again XX denotes the country acronym.

For the estimation of the TVP-VAR we use monthly time series for Ireland, Italy, Portugal and Spain and aggregate it to time series for the euro area periphery by using nominal GDPs as weight. Since the time series for nominal GDP, which are taken from the Eurostat database, are only available on a quarterly frequency, we assume weights to remain constant within a given quarter. Figure 6 shows the complete time series that we use for estimation, including the training sample of 36 month.

Figure 6: Periphery Time Series
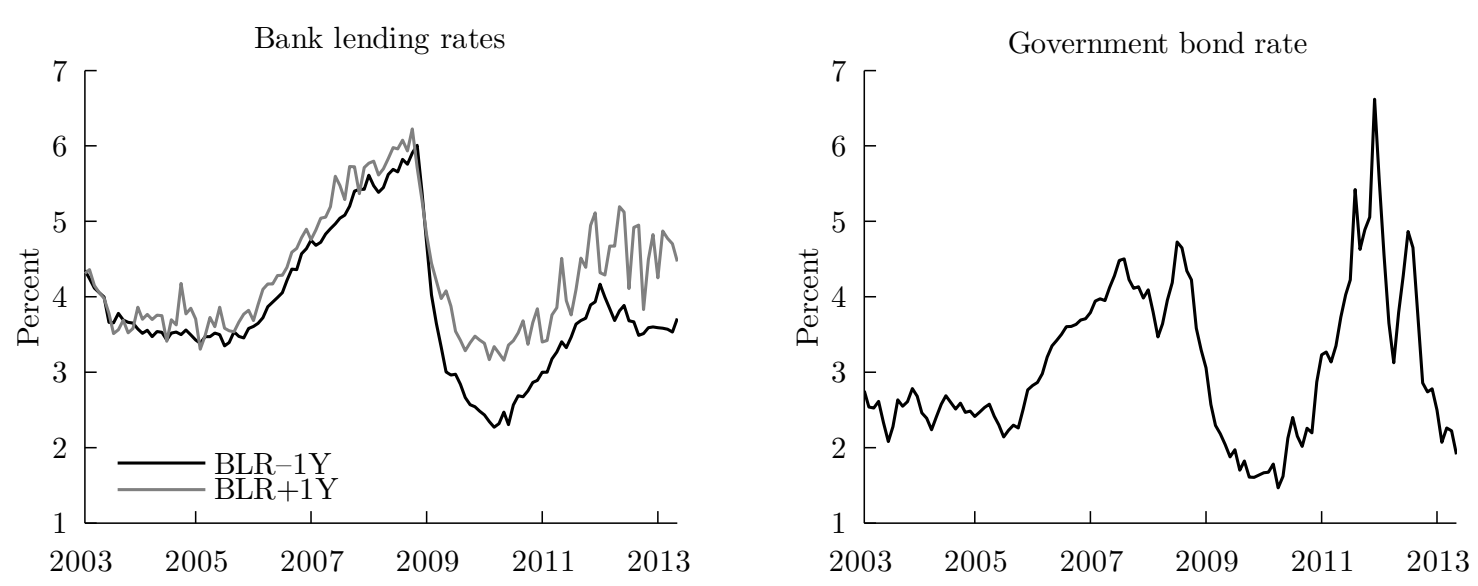


\section{B Markov-Chain Monte-Carlo Algorithm}

The parameters of the TVP-VAR models as well as various statistics of interest are estimated by means of a version of the Markov-Chain Monte-Carlo (MCMC) algorithm. In particular, the unconditional posterior distributions of $Q, S$ and $W$ are approximated by draws from their conditional posterior distributions, the time paths $\left\{B_{t}\right\}_{t=T_{0}+1}^{T}$ and $\left\{\alpha_{t}\right\}_{t=T_{0}+1}^{T}$ are computed by using the Carter-Kohn algorithm while we resort to the independence Metropolis-Hastings approach for inferring the time paths of the stochastic volatilities $\left\{\log \sigma_{t}\right\}_{t=T_{0}+1}^{T}$, where $T$ and $T_{0}$ denote the size of the overall and the training sample respectively. The algorithm includes the following steps:

1. Set priors for $Q, S, W, B_{0}, \alpha_{0}$ and $\log \sigma_{0}$.

2. Choose starting values for $Q, S$ and $W$ : We use $\operatorname{diag}\left(Q_{\text {start }}\right)=V\left(\hat{B}_{O L S}\right)$, $\operatorname{diag}\left(S_{\text {start }}\right)=V\left(\hat{A}_{O L S}\right)$ and $\operatorname{diag}\left(W_{\text {start }}\right)=\operatorname{diag}\left(I_{2}\right) * 0.0001$.

3. Choose starting values for the Carter-Kohn algorithm: Following (Primiceri, $2005)$ we set $B_{0}=\hat{B}_{O L S}, P_{B, \text { start }}=4 \cdot V\left(\hat{B}_{O L S}\right), \alpha_{0}=\hat{A}_{O L S}, P_{A, \text { start }}=$ $4 \cdot V\left(\hat{A}_{O L S}\right)$, where $P_{B}$ and $P_{A}$ denote the covariance matrices of the initial state vectors $B_{0}$ and $\alpha_{0}$. Note that in our case $\alpha_{0}$ is a scalar.

4. Set priors for the Metropolis-Hastings algorithm (used to infer the path of $\sigma_{t}$ ): We resort to $\log \sigma_{0} \sim N(\bar{\mu}, \bar{\sigma})$ with $\bar{\mu}=\log \hat{\sigma}_{O L S}$ and $\bar{\sigma}=\operatorname{diag}\left(I_{n}\right) \cdot 10$.

5. Specify a starting value for the time path $\left\{\alpha_{t}\right\}_{t=T_{0}+1}^{T}$ : We set $\alpha_{t, \text { start }}=\hat{A}_{O L S}$ for all $t=T_{0}+1, \ldots, T$.

6. Specify a starting value for the time path of $\left\{\sigma_{t}\right\}_{t=T_{0}+1}^{T}$ : We set $\sigma_{1, t, \text { start }}=$ $u_{1, O L S}^{2}$ and $\sigma_{2, t, \text { start }}=u_{2, O L S}^{2}$ for all $t=T_{0}+1, \ldots, T$, where $u_{1, O L S}^{2}$ and $u_{2, O L S}^{2}$ are the OLS estimates of the variances of the reduced form residuals based on the training sample.

7. Set $Q=Q_{\text {start }}, S=S_{\text {start }}, W=W_{\text {start }}, \alpha_{t}=\alpha_{t, \text { start }}$ and $\log \sigma_{t}=\log \sigma_{t, \text { start }}$.

8. Conditional on $Q, \alpha_{t}$ and $\log \sigma_{t}$ draw a new time path $\left\{B_{t}\right\}_{t=T_{0}+1}^{T}$ by using the Carter-Kohn algorithm.

9. Given the draw for the time path $\left\{B_{t}\right\}_{t=T_{0}+1}^{T}$ calculate the corresponding draw for the time path of the vector of residuals $\nu_{t}=B_{t}-B_{t-1}$, for $t=T_{0}+1, \ldots, T$.

10. Conditional on the draw for $\left\{\nu_{t}\right\}_{t=T_{0}+1}^{T}=\bar{\nu}$ draw the $i$ th diagonal element of the diagonal matrix $\tilde{Q}$ from the inverse Gamma distribution with scaling 
parameter equal to the $i$ th element of $\left(\operatorname{diag}\left(\bar{\nu}^{\prime} \bar{\nu}\right)+k_{Q}^{2} \cdot T_{0} \cdot V\left(\hat{B}_{O L S}\right)\right) / 2$ and degrees of freedom $\left(T_{0}+T-T_{0}\right) / 2$. If $Q$ is allowed to be non-diagonal, draw $\tilde{Q}$ from the inverse Wishart distribution with scaling matrix $\bar{\nu}^{\prime} \overline{\nu_{t}}+k_{Q}^{2} \cdot T_{0} \cdot V\left(\hat{B}_{O L S}\right)$ and degrees of freedom $T_{0}+T-T_{0}$.

11. Conditional on $S,\left\{\log \sigma_{t}\right\}_{t=T_{0}+1}^{T}$ and the new draw $\left\{B_{t}\right\}_{t}=T_{0}+1^{T}$ draw a new time path $\left\{\alpha_{t}\right\}_{t=T_{0}+1}^{T}$ using the Carter-Kohn algorithm.

12. Given the new draw for $\left\{\alpha_{t}\right\}_{t=T_{0}+1}^{T}$ calculate the corresponding draw for the residuals $\zeta_{t}=\alpha_{t}-\alpha_{t-1}$ for $t=T_{0}+1, \ldots, T$.

13. Conditional on the draw for $\left\{\zeta_{t}\right\}_{t=T-0+1}^{T}=\bar{\zeta}$ draw the $\tilde{S}$ from the inverse Gamma distribution with scaling parameter $\left(\bar{\zeta}^{\prime} \bar{\zeta}+k_{S}^{2} \cdot 2 \cdot V\left(\hat{A}_{O L S}\right)\right) / 2$ and degrees of freedom $\left(T-T_{0}-1\right) / 2$. Note that in our case $\alpha_{t}$ is a scalar.

14. Conditional on the draws for $\left\{B_{t}\right\}_{t=T-0+1}^{T}$ and $\left\{\alpha_{t}\right\}_{t=T-0+1}^{T}$ calculate a new draw for the structural residuals $\epsilon_{t}=A_{t} u_{t}$, for $t=T_{0}+1, \ldots, T$.

15. Conditional on $W$ and the draw $\left\{\epsilon_{t}\right\}_{t=T_{0}+1}^{T}$ use the independence MetropolisHastings algorithm (with parameters $\bar{\mu}$ and $\bar{\sigma}$ ) to derive a new draw for $\left\{\sigma_{t}\right\}_{t=T_{0}+1}^{T}$. Note that, since the two structural residuals in our model, $\epsilon_{1, t}$ and $\epsilon_{2, t}$ are mutually uncorrelated, the corresponding paths of the variances $\left\{\sigma_{1, t}\right\}_{t=T_{0}+1}^{T}\left(\left\{\sigma_{2, t}\right\}_{t=T_{0}+1}^{T}\right)$ are computed based on $\left\{\epsilon_{1, t}\right\}_{t=T_{0}+1}^{T}\left(\left\{\epsilon_{2, t}\right\}_{t=T_{0}+1}^{T}\right)$ only.

16. Given the new draw for $\left\{\sigma_{t}\right\}_{t=T_{0}+1}^{T}$ compute $\eta_{t}=\log \sigma_{i}-\log \sigma_{i, t-1}$, for $t=T_{0}+$ $1, \ldots, T$. Given $\left\{\eta_{t}\right\}_{t=T_{0}+1}^{T}=\bar{\eta}$ draw the $i$ th diagonal element of the diagonal matrix $\tilde{W}$ from the inverse Gamma distribution with scaling parameter equal to the $i$ th element of $\frac{\operatorname{diag}\left(\bar{\eta}^{\prime} \bar{\eta}\right)+k_{W}^{2} \cdot 3}{2}$ and degrees of freedom $\left(T-T_{0}\right) / 2$.

17. Set $Q=\tilde{Q}, S=\tilde{S}$ and $W=\tilde{W}$.

18. Repeat steps 8 through $17 X$ times. Discard the burn-in draws. The remaining draws are used to compute the statistics of interest. 


\section{Marginal Likelihood}

Let $\theta=(Q, S, W), \vartheta=\left(\left\{B_{t}\right\}_{t=T_{0}+1}^{T},\left\{\alpha_{t}\right\}_{t=T_{0}+1}^{T},\left\{\sigma_{t}\right\}_{t=T_{0}+1}^{T}\right)$ and $Y=\left\{Y_{t}\right\}_{t=T_{0}+1}^{T}$. The marginal likelihood for our model $F(Y)$ is defined as the integral

$$
F(Y)=\int f(Y \mid \theta ; \vartheta) \pi(\theta) d \theta
$$

where $f(Y \mid \theta ; \vartheta)$ denotes the likelihood function of the model while $\pi(\theta)$ denotes the joint prior density of the parameters. Accordingly, the marginal likelihood corresponds to the posterior distribution with the parameters integrated out. Since for our TVP-VAR the above integral can not be evaluated analytically, we follow Nakajima (2011) and approximate it by the method suggested by Gelfand and Dey (1994):

$$
\frac{1}{F(Y)} \approx \frac{1}{N_{\text {draws }}} \cdot \sum_{j=1}^{N_{\text {draws }}} \frac{\phi\left(\theta_{j}\right)}{f\left(Y \mid \theta_{j} ; \vartheta_{j}\right) \pi\left(\theta_{j}\right)}
$$

where $N_{\text {draws }}$ is the number of MCMC draws, $\theta_{j}$ denotes the $j$ th draw of $\theta$ and $\phi\left(\theta_{j}\right)$ is the probability density function of the truncated normal distribution recommended by Geweke (1994). In particular

$$
\phi\left(\theta_{j}\right)=\frac{1}{(1-\tau)(2 \pi)^{\frac{K}{2}}}|\Upsilon|^{-\frac{1}{2}} \exp \left[-\frac{1}{2}\left(\theta_{j}-\bar{\theta}\right)^{\prime} \Upsilon^{-1}\left(\theta_{j}-\bar{\theta}\right)\right] \cdot \mathbb{I},
$$

where $\bar{\theta}$ is the posterior mean and $\Upsilon$ the posterior covariance matrix of the parameter vector $\theta . K$ is the number of elements in $\theta . \mathbb{I}$ denotes the indicator function taking the value of one if

$$
\left(\theta_{j}-\bar{\theta}\right)^{\prime} \Upsilon^{-1}\left(\theta_{j}-\bar{\theta}\right) \leq \chi_{\tau}^{2}(K)
$$

and zero otherwise. $\chi_{\tau}^{2}(K)$ denotes the $\tau^{t h}$ percentile of the inverse $\chi^{2}$-distribution with $K$ degrees of freedom. Following Nakajima (2011) we set $\tau=0.99$. 


\section{Bazooka Mario Rap}

A tribute from the bankers

-1- Our Mario

floods us with liquidity

attempts to court our sympathy

asks us to do some serious bond buying

but we are denying

Bazooka, zooka Mario (x2)

Yo! Mario!

thanks for the liquidity

but due to limited financial ability

we store everything in the deposit facility

Bazooka, zooka Mario (x2)

-2- Our Mario

gives us the cash

to prevent the crash

he wants us to extend bank lending

to stimulate domestic spending

Bazooka, zooka Mario (x2)

Yo! Mario!

due to frayed nerves

we hold all cash in the form of excess reserves

we don't care about stimulation

we keep on the economic strangulation

Bazooka, zooka Mario (x2) 
-3- Our Mario

recognized our denial to provide sovereign liquidity transfusion

launched the OMT program to create the illusion

that monetary policy stands ready to solve all things

now we rely on Mario and see what it brings

Bazooka, zooka Mario (x2)

Yo! Mario!

anyway we refuse to reduce lending rates

no matter if the economy breaks

but we pay low rates on deposits

thanks for improving short-run profits

Bazooka, zooka Mario (x2)

-4- Our Mario

would ascend the bankers' throne

by announcing to buy every non-performing loan

call this program the ECB's death star

because this one would go so far

Bazooka, zooka Mario (x2)

Yo! Mario!

much better than the bazooka, the death star

would allow us to bath daily in Beluga caviar

Beluga, luga Mario (x2)

This song is dedicated to all economist brothers and sisters working at the ECB. It shouldn't be taken too seriously. Lyrics should best be rapped to the beat of Bazooka Joe by Bazooka Joe available at http: //www . youtube. com/watch?v=yZXRaVBfOpY. 